\title{
The competitive advantage of serendipity in the case of Starbucks and Howard Schultz
}

\author{
Tam-Tri Le \\ Centre for Interdisciplinary Social Research \\ Phenikaa University, Hanoi, Vietnam \\ 2022 January 17 \\ OSF Preprints
}

Many urban people around the world are quite familiar with Starbucks - a famous brand of multinational coffeehouse chain. In 2021, the corporate had net revenue of nearly 25 billion USD. But back in the 1970s and early 1980s, Starbucks was only a medium-size company selling coffee beans and brewing machines in the local area of Seattle, Washington. In 1983, Howard Schultz - working as Starbucks' Director of Retail Operations and Marketing at the time - was sent to Milan to attend a conference. While in Italy, Schultz took a detour from the conference and visited local cafés to see the European culture of coffee consumption. Upon observing the locals, Schultz realized that many Italian people did not come to cafés just for the sake of drinking coffee but rather to spend time together and talk with other customers. This serendipity moment gave Schultz the idea that instead of simply selling coffee, Starbucks should focus more on the café's settings, serving as a place for communal activities and interactions - in other words, a social hub. The direction change later led to the exponential growth of Starbucks chains in the US as well as global expansion. Howard Schultz held the position of Starbucks' chief executive officer (CEO) from 1986 to 2000 and again from 2008 to 2017. As of December 2021, Schultz is a billionaire with an estimated net worth of about 5 billion USD [1].

Howard Schultz's ability to notice the value of the information about Milan's local coffee culture in relation to the company's business helped him achieve great success in his career, improving his wealth and the status of his identity. It is also worth noting that in Schultz's early life, his family was relatively poor, meaning that there should have been a high degree of "survival" stresses. The desire to become successful in his career was a strong motive. In other words, the big question of how to achieve that purpose was in the back of his mind, thus serving as the navigation and condition for the directional connection of values when the "missing piece" was recognized - a serendipity moment. Regarding the aspect of social competitions (comparing with other fellow humans), Schultz's skills for catching that particular serendipity moment in the early 1980s (when others did not) paid off wonderfully. It gave him massive advantages in terms of social survival (e.g. financial gain, security, control, and influence). Additionally, Schultz will surely leave behind a noticeable legacy (prolonging the existence of his representative values) even when he is gone.

The significance of the social survival aspect can also be seen on collective levels. The status of the Starbucks company in the early 1980s was the background condition for Schultz's discovery. 
A strong desire for growth was a shared value within the company's collective mindset at the time, which, likewise, expressed as the lingering question "how". Suppose that the company has had no desires for growth and competition at all, they would not have welcomed the sudden innovative idea from Schultz. Regarding the impact of the innovation, it is obvious how much Starbucks has outcompeted other companies in the business. The existence of their brand in society has been greatly reinforced, and the chain has been expanded widely all over the globe. Naturally, all businesses today highly value serendipity for the competitive advantage it brings [2]. It is clear that the right investment for research and development is worth its costs [3].

We can look at this story on an integral information process of innovation [4]. The information filtering that helped Schultz connect the new values from his observation to the company's business schemes follows the Mindsponge mechanism [5,6]. Regarding the 3D principles of creativity [7], this example demonstrated well the "out-of-discipline" aspect.

Update: More detailed discussions in the full book "A New Theory of Serendipity: Nature, Emergence and Mechanism" [8] (see References).

\section{Acknowledgement}

I would like to thank my mentor Dr. Quan-Hoang Vuong and my friend Minh-Hoang Nguyen for the insights.

\section{References}

1. Forbes. (2021). Howard Schultz. Forbes. Retrieved from https://www.forbes.com/profile/howard-schultz/

2. Napier, N., \& Vuong, Q. H. (2013). Serendipity as a Strategic Advantage? In T. Wilkinson (Ed.), Strategic Management in the 21st Century (pp. 175-199). Westport, CT: Praeger/ABC-Clio.

3. Vuong, Q.-H. (2018). The (ir)rational consideration of the cost of science in transition economies. Nature Human Behaviour, 2(1), 5. doi:10.1038/s41562-017-0281-4

4. Vuong, Q.-H., et al. (2022). Covid-19 vaccines production and societal immunization under the serendipity-mindsponge-3D knowledge management theory and conceptual framework. Humanities and Social Sciences Communications, 9, forthcoming.

5. Vuong, Q. H., \& Napier, N. K. (2015). Acculturation and global mindsponge: An emerging market perspective. International Journal of Intercultural Relations, 49, 354-367. doi:10.1016/j.ijintrel.2015.06.003

6. Nguyen, M.-H., et al. (2021). Alice in Suicideland: Exploring the Suicidal Ideation Mechanism through the Sense of Connectedness and Help-Seeking Behaviors. International Journal of Environmental Research and Public Health, 18(7), 3681. doi:10.3390/ijerph18073681

7. Vuong, Q. H., \& Napier, N. K. (2014). Making creativity: the value of multiple filters in the innovation process. International Journal of Transitions and Innovation Systems, 3(4), 294-327. doi:10.1504/IJTIS.2014.068306 
8. Quan-Hoang Vuong. (2022). A New Theory of Serendipity: Nature, Emergence and Mechanism. Berlin, Germany: De Gruyter. 